\title{
Kernos
}

Revue internationale et pluridisciplinaire de religion grecque antique

34 | 2021

Varia

\section{The World of Greek Religion and Mythology}

\author{
Vinciane Pirenne-Delforge
}

\section{QpenEdition \\ Journals}

\section{Édition électronique}

URL : https://journals.openedition.org/kernos/4030

DOI : 10.4000/kernos.4030

ISSN : 2034-7871

\section{Éditeur}

Centre international d'étude de la religion grecque antique

\section{Édition imprimée}

Date de publication : 31 décembre 2021

Pagination : $314-315$

ISBN : 978-2-87562-305-8

ISSN : 0776-3824

\section{Référence électronique}

Vinciane Pirenne-Delforge, "The World of Greek Religion and Mythology », Kernos [En ligne], 34 | 2021, mis en ligne le 31 décembre 2021, consulté le 15 mars 2023. URL : http://journals.openedition.org/ kernos/4030; DOI : https://doi.org/10.4000/kernos.4030

Ce document a été généré automatiquement le 15 mars 2023.

Tous droits réservés 


\title{
The World of Greek Religion and Mythology
}

\author{
Vinciane Pirenne-Delforge
}

\section{RÉFÉRENCE}

Jan N. BREMMER, The World of Greek Religion and Mythology, Tübingen, Mohr Siebeck, 2019. 1 vol. 16,5 × 23,5 cm, 564 p. (Wissenschaftliche Untersuchungen zum Neuen Testament, 43).

ISBN : 978-3-16-154451-4.

1 Jan N. Bremmer (J.N.B.) est incontestablement un historien des religions antiques parmi les plus productifs de ces quarante dernières années, qu'il s'agisse de l'étude du monde gréco-romain ou du christianisme antique, qu'il arpente avec une remarquable maîtrise des outils nécessaires à cette fin. Aux débuts du christianisme était consacré le premier recueil de ses travaux publié chez Mohr Siebeck ${ }^{1}$, tandis que ce deuxième volume (qui n'est pas le second ${ }^{2}$ ) rassemble, en trente chapitres, 35 articles dont les dates de publication initiale s'échelonnent de 1984 à 2017. Un bref appendice biographique analysant le point de vue critique du néerlandais Gerardus van der Leeuw (et d'autres) sur Jane Ellen Harrison s'ajoute à l'ensemble, qui se referme sur un index unique où apparaissent à la fois des noms, des thèmes et des sources.

2 Les trente chapitres du livre se répartissent en quatre parties, respectivement intitulées Gods and Heroes (I), Aspects of Greek Religion (II), Animal and Human Sacrifice (III) et Myth (IV). Sans entrer dans le détail de chaque partie ${ }^{3}$, soulignons la cohérence thématique des ensembles que forment les sections I, III et IV. La deuxième est plus hétéroclite et rassemble des études sur la magie, certaines conceptions eschatologiques, la figure du devin, celle de la femme âgée, le secret des mystères, le ménadisme et les relations entre religion grecque et Proche-Orient ancien.

3 Ce que l'on appelait naguère des Kleine Schriften est une entreprise éditoriale peut-être moins nécessairement urgente à l'heure du numérique que par le passé, quand des articles publiés dans des recueils confidentiels ou d'obscures revues restaient 
inaccessibles. Néanmoins, on ne boudera pas le plaisir que procure, au temps du PDFroi, le fait de pouvoir prendre en main un bel objet, bien édité et bien relié. En outre et surtout -, son contenu a été pensé et ordonné par son auteur qui jette ainsi un regard rétrospectif sur son propre travail. Il assortit cette moisson d'une démarche rarement adoptée dans ce type de florilège puisque les articles n'ont pas forcément été republiés à l'identique : des titres ont été transformés, certains points ont été réécrits et la bibliographie a été mise à jour dans les notes. Dans la préface où il explique son parti-pris, J.N.B. écrit que « this could not be done in every case, but [he has] always tried to bring the volume up to date with regard to the more important issues ", ce qui implique des choix quelque peu aléatoires, il faut bien le reconnaître. Les chapitres 16 (Greek Religion and the Ancient Near East) et 17 (Animal Sacrifice) ont quant à eux été restitués dans leur texte original, qui avait dû être abrégé à l'époque de la première publication pour correspondre aux attentes des ouvrages collectifs dans lesquels ils s'inséraient. Les objets éditoriaux ainsi (re)produits risquent de donner des maux de tête et quelques cheveux blancs aux chercheurs établissant des bibliographies, mais c'est une forme de valeur ajoutée au présent volume. C'est aussi un risque, car ajouter des références bibliographiques ne suffit pas à faire droit à l'argumentation de ce que l'on cite. Dans bien des cas, la prise en compte de travaux récents imposait idéalement d'en affronter le contenu dans le corps de l'article lui-même. C'eût été un tout autre travail de mise à jour, et celui qui a été consenti - déjà considérable - reste plus descriptif et cumulatif que véritablement argumentatif. Quoi qu'il en soit, l'inlassable curiosité de l'A. et sa prodigieuse érudition donneront à tous les lecteurs maintes clés pour entrer dans le foisonnant domaine de la religion grecque, que ce soit par le biais de la figure de ses dieux et héros, par le biais de ses cultes, de ses rituels spécifiques ou de ses mythes qui sont, comme le souligne justement J.N.B., partie intégrante de cette religion.

\section{NOTES}

1. J.N. BREMMER, Maidens, Magic and Martyrs in Early Christianity. Collected Essays I, Tübingen, 2017. Un volume publié chez Brill en 2008 rassemblait déjà dix-huit contributions (1992-2008) sous le titre Greek Religion and Culture, the Bible and the Ancient Near East.

2. Puisqu'un autre, portant sur le thème de l'initiation, est annoncé : Becoming a Man in Ancient Greece and Rome: Myths and Rituals of Initiation, Tübingen, forthcoming.

3. On en trouvera le détail dans le compte rendu du livre donné, en français, par M. Lesgourgues dans la Bryn Mawr Classical Review (https://bmcr.brynmawr.edu/2021/2021.06.15/). 


\section{AUTEURS}

\section{VINCIANE PIRENNE-DELFORGE}

Collège de France, Université de Liège 